\title{
Development of Functionalized silver Nanoparticles from Allamanda neriifolia Hook and their In Vitro Cytotoxic Effect on MCF-7 Cells
}

\author{
Sumathi $\mathbf{R}^{\# 1}$, Sivagamasundari $\mathbf{K}^{* 2}$ \\ 1. Assistant Professor\& Head, PG and Research Department of Biochemistry, Rabiammal Ahamed \\ Maideen College for women, Thiruvarur.Tamilnadu, India. sumathiraguraman@ymail.com \\ 2. Research Scholar, PG and Research Department of Biochemistry, Rabiammal Ahamed Maideen \\ College for women, Thiruvarur. Tamilnadu, India. \\ Corresponding Author: Sumathi R
}

\begin{abstract}
The present work demonstrates the influence of plant extract composition (antioxidant and total phenolic content) on the size and morphology of the produced AgNPs. In this study, silver nanoparticles (AgNPs) were synthesized using aqueous flower extract of Allamanda neriifolia plant. The biosynthetic procedure was rapid and simple and was easily monitored via colour changes and examined AgNPs (AN-AgNPs) by ultraviolet-visible spectroscopy, Fourier transform infrared (FTIR) spectroscopy and scanning electron microscope (SEM). The results obtained from various characterizations revealed that average size of synthesized AgNPs was $50 \mathrm{~nm}$ and in spherical structure. The anticancer potential of AN-AgNPs was investigated against human breast cancer cells (MCF-7). The cytotoxic response was assessed by 3-(4, 5-dimethylthiazol-2-yl)-2, 5-diphenyltetrazolium bromide (MTT), and morphological changes by apoptosis. The biosynthesized AgNPs-induced cell death in MCF7 cells suggested the anticancer potential of AN-AgNPs. Therefore, they may be used to treat the breast cancer cells.
\end{abstract}

Key Words: AN-AgNPs, anticancer, cytotoxicity, ROS, apoptosis, nanoparticles

\section{INTRODUCTION}

Nanoparticles are simply defined as particles in the $10^{-9} \mathrm{~nm}$ range. Comparing this size, a human hair is said to be approximately $70000 \mathrm{~nm}$ in diameter, a red blood cell about 5000 $\mathrm{nm}$ and some simple organic molecules falls within 0.5-5 nm range (Mohanraj and Chen, 2006). Nanotechnology/nanobiotechnology, on the other hand, simply denotes the man-made use of these nano-sized particles, for industrial and medical purposes. Application depends on the unique properties of each type of nanoparticle (Biswas and $\mathrm{Wu}, 2005$ ).

Nanotechnology is one of the most active research areas in modern materials science. Nanoparticles exhibit new or improved properties based on specific characteristics such as 
size, distribution and morphology. There have been impressive developments in the field of nanotechnology in the recent past years, with numerous methodologies developed to synthesize nanoparticles of particular shape and size depending on specific requirements. New applications of nanoparticles and nanomaterials are increasing rapidly (Malam et al., 2011).

Nanotechnology can be termed as the synthesis, characterization, exploration and application of nanosized (1-100 nm) materials for the development of science. It deals with the materials whose structures exhibit significantly novel and improved physical, chemical and biological properties, phenomena, and functionality due to their nano scaled size. Because of their size, nanoparticles have a larger surface area than macro-sized materials. The intrinsic properties of metal nanoparticles are mainly determined by their size, shape, composition, crystallinity and morphology (Sun and Xia, 2002).

Medicinal plants have served as rich sources of pharmacologically active substances. Herbs have been used in a diverse array of purposes, including medicine, nutrition, flavoring, dying, repellents, fragrances, cosmetic, charms, smoking and industrial uses. Today, herbs are still found in $40 \%$ of prescription drugs (Newman, \& Cragg, 2007).

Allamanda neriifolia HOOK, locally known as yellow bell belongs to the family Apocynaceae, commonly known as oleander or dogbane family with about 200 genera and 2,000 species are most commonly found in tropical and subtropical regions. Some species are familiar as ornamental plants cultivated for their large, colorful flowers. Most of the species produce yellow flowers. A. neriifolia is $u$ sed to treat gastrointestinal ailments, fever, malaria, pain and diabetes, including skin and ecto-parasitic diseases. Non-medicinal uses include food, poisons, fodder, wood, ornamentals, dye and perfume (Siu Kuin Wong et al., 2013). Allamanda species had several chemical compounds; including iridoid lactones such as allamandin, plumericin, and plumierides. Due to the presence of these compounds this flower exhibit antineoplastic, antileukemic, antiinflammatory, antimicrobial, and antileishmanial activities (Castillo et al., 2007) antidermatophytic and antitumor activities (Tiwari et al., 2002).

The extract of various plants grown in farms is used permanently for the biosynthesis of nanoparticles, but whether the plants grown under in vitro condition have this ability or not is still under scrutiny. The main purposes of this work are considering the potential of the plant extract of A.neriifolia grown in vitro for the biosynthesis of Ag NPs and investigation of their anticytotoxic activities.

\section{MATERIALS AND METHODS}

\section{Chemicals}

Dulbecco's Modified Eagle's Medium (DMEM), fetal bovine serum (FBS), glutamine, penicillin-streptomycin and trypsin neutralizer solution were purchased from Himedia, India. 3-(4,5-dimethylthiazol-2-yl)-2,5-diphenyl-tetrazolium bromide (MTT), 2,7diacetyl dichlorofluorescein (DCFH-DA), Ethidium bromide and Acridine Orange were purchased from Sigma-Aldrich (St. Louis, Missouri, USA). All other chemicals used in this study were of analytical grade obtained from E. Merck and HIMEDIA, India. 


\section{Preparation of Allamanda neriifolia flower extract}

The freshly collected Allamanda flower extract were collected and washed several times with distilled water to remove dust and was dried under shade for two weeks and ground into fine powder. The powder (50 g) was taken in a $500 \mathrm{ml}$ beaker containing $250 \mathrm{ml}$ of distilled water and kept for stirring at room temperature for $5 \mathrm{~h}$. The extract was filtered and the filtrate was centrifuged at 10,000 rpm for 10min and then the supernatant was kept in the freezer overnight and then lyophilized under vacuum. The dried extract was kept at $4{ }^{\circ} \mathrm{C}$.

\section{Biosynthesis of silver nanoparticles}

$30 \mathrm{mg}$ of silver nitrate $\left(\mathrm{AgNO}_{3}\right)$ was dissolved in $180 \mathrm{~mL}$ of deionized water so as to obtain $0.1 \mathrm{mM}$ of silver nitrate precursor solution. $20 \mathrm{~mL}$ of Allamanda flower extract was added to this solution and the mixture was magnetically stirred for $30 \mathrm{~min}$. The mixture solution which initially appeared in pale green colour, slowly changed into brownish red colour within $2 \mathrm{~h}$. The colour change indicated the formation of silver nanoparticles and the completion of the synthesis process. The reacted solution was centrifuged at a speed 1,200 rpm for $15 \mathrm{~min}$ and the nanoparticles settled at the bottom were carefully removed and spread on a Petri dish for drying at $35^{\circ} \mathrm{C}$. Finally, the nano powder was collected and gently crushed in an agate mortar.

\section{Protocol for synthesis of silver nanoparticles using Allamanda neriifolia flower extract Characterization of silver nanoparticles}

The optical absorption of green synthesized silver nanoparticles was studied to determine their size and morphological characteristics with the help of UV-Visible spectroscopy (Shimadzu UV-VIS 2550, Japan), Fourier-transform infrared spectroscopy (FTIR, Shimadzu, IR Affinity 1, Japan) and Scanning electron microscope studies (SEM).

\section{Ultra Violet-Visible spectrum analysis}

The bio reduction of silver nitrate $\left(\mathrm{AgNO}_{3}\right)$ to $\mathrm{AgNPs}$ was monitored periodically by UV-Vis spectroscopy after the dilution of the samples with deionized water. A UV-Vis spectrograph of the silver and nanoparticles was recorded by using a quartz cuvette with water as reference. The UV-Vis spectrometric readings were recorded at a scanning speed of 200-800 nm.

\section{Fourier Transform Infrared spectroscopy (FTIR) Analysis}

Fourier Transform Infrared Spectrophotometer is perhaps the most powerful tool for identifying the types of chemical bonds (functional groups) present in compounds. The wavelength of light absorbed is characteristic of the chemical bond as can be seen in the annotated spectrum. By interpreting the infrared absorption spectrum, the chemical bonds in a molecule can be determined. Dried powder of different solvent extracts of each plant materials was used for FTIR analysis. $10 \mathrm{mg}$ of the dried extract powder was encapsulated in $10 \mathrm{mg}$ of $\mathrm{KBr}$ pellet, in order to prepare translucent sample discs. The powdered sample of each plant specimen was loaded in FTIR spectroscope, with a Scan range from 400 to 4000 $\mathrm{cm}^{-1}$ with a resolution of $4 \mathrm{~cm}^{-1}$. 


\section{Scanning Electron Microscopy (SEM) analysis}

SEM study was performed to study shape, size and surface area of the AgNPs. The AgNPs solutions were ultra-sonicated at room temperature for $15 \mathrm{~min}$ and one drop of the sample was placed on a glass slide. After drying, the glass slide was coated with gold and visualized under SEM.

\section{Invitro cytotoxicity Assay MCF-7 cell culture}

MDA-MB-231 cells were purchased from NCCS, Pune in DMEM with 10\% FBS, $1 \%$ glutamine, and $1 \%$ penicillin-streptomycin at $37{ }^{\circ} \mathrm{C}$ in a humidified atmosphere with $5 \%$ $\mathrm{CO}_{2}$ incubator. For sub culturing, a monolayer of cells was washed with phosphate-buffered saline (PBS), trypsinized for $2-3 \mathrm{~min}$ at $37^{\circ} \mathrm{C}$, and dispensed into fresh culture flasks containing medium. Cell cultures between passages 3 to 5 were used for each experiment.

\section{MTT assay}

The cytotoxic effect of AN-AgNPswas determined by MTT assay based on the detection of mitochondrial dehydrogenase activity in living cells (Mosmann, 1983).

\section{Principle}

MTT (3-(4, 5-dimethylthiazol-2-yl)-2, 5-diphenyl-tetrazolium bromide) assay, the yellow tetrazolium salt is metabolized by NAD-dependent dehydrogenase (in active mitochondria) to form a dark blue formazan product.

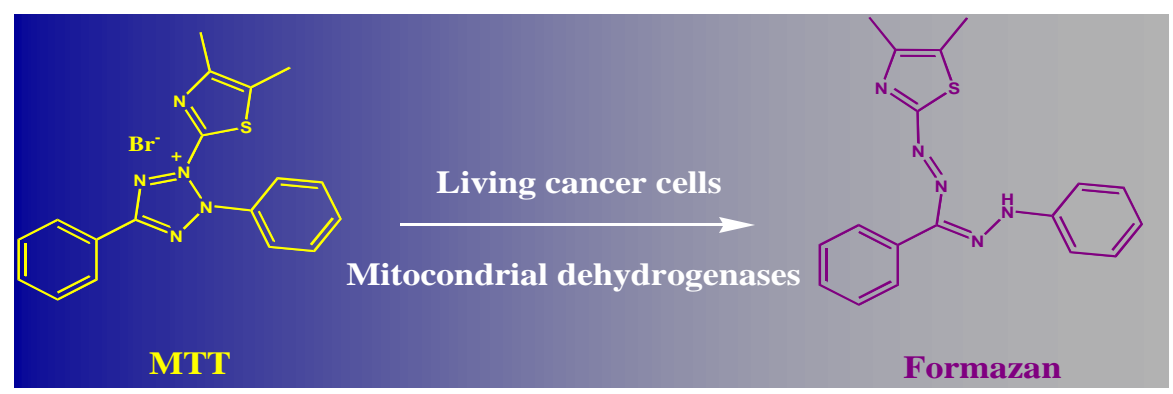

\section{Materials}

1. 0.5 g/LMTT (3-(4, 5-dimethylthiazol-2-yl)-2, 5-diphenyl-tetrazolium bromide)

2. Dimethyl sulfoxide (DMSO)

3. 96 well plate

4. Micro plate reader

\section{Procedure}

Cultured MDA-MB-231 ( $1 \times 10^{6}$ cells/mL) was taken into a 96 well plate. Then the cells were pretreated with different concentration of AN-AgNPs $(1,5,10,20,40,80,100$, $200,400,500 \mu \mathrm{g})$. Then the cells were incubated at $5 \% \mathrm{CO}_{2}$ and $95 \% \mathrm{O}_{2}$ environment at 37 ${ }^{\circ} \mathrm{C}$ for $24 \mathrm{~h}$. MTT $(0.5 \mathrm{mg} / \mathrm{mL})$ was added to the incubated cells and then further incubated for another $4 \mathrm{~h}$. The cells were centrifuged for $10 \mathrm{~min}$ and the supernatant was removed, 200 $\mu \mathrm{L}$ of DMSO were added into each tube. Absorbance was measured in a microplate reader at 
$540 \mathrm{~nm}$. Images captured under microscope. Percentage cytotoxicity was calculated as follows:

$$
\% \text { Cytotoxicity }=\quad \frac{\text { Test optical density }}{\text { Control optical density }} \times 100
$$

\section{Experimental design}

MDA-MB-231 cells treated with AN-AgNPs (10, 20 and $40 \mu \mathrm{g} / \mathrm{ml})$ then cellular changes were analyzed after $24 \mathrm{~h}$ of incubation. Cultured MDA-MB-231 was divided into four groups as follows:

$$
\begin{aligned}
& \text { Group } 1 \quad \text { Control cells } \\
& \text { Group } 2 \quad: \text { AC-AgNPs }(10 \mu \mathrm{g}) \\
& \text { Group } 3 \quad: \text { AC-AgNPs }(20 \mu \mathrm{g}) \\
& \text { Group } 4 \quad: \text { AC-AgNPs }(40 \mu \mathrm{g})
\end{aligned}
$$

\section{Statistical Analysis}

All quantitative measurements were expressed as means \pm SD for control and experimental cells. The data were analyzed using one way analysis of variance (ANOVA) on SPSS (statistical package for social sciences) and the group means were compared by Duncan's Multiple Range Test (DMRT). The results were considered statistically significant if the $\mathrm{P}$ value is less than 0.05 .

\section{RESULTS AND DISCUSSION \\ Synthesis of silver nanoparticles}

In the present study, synthesis of AgNPs was performed using flower extract of Allamanda neriifolia and their biological activities were also assessed under invitro condition. The characterization of nanoparticles is usually done based on their shape, size, surface area and dispersion. In our study, the flower extract of Allamanda changed its colour from yellow to light brown and, eventually, to dark brown when mixed with $\mathrm{AgNO}_{3}$ at room temperature within $1 \mathrm{~h}$ of incubation (Figure A \& B). Thus, it could be used for its ample applications in various fields (Jiang et al., 2009). This is in agreement with the finding of the previous researchers who reported that the colour change is an indication of the formation of AgNPs in various plant systems (Philip, 2011; Swamy et al., 2015 ), while, the plant extract devoid of $\mathrm{AgNO}_{3}$ showed no changes in colour and remained as green. Ahmad et al. (2011) explained the main reason behind the colour change is the surface plasmon resonance of the metal nanoparticles. However, the reaction time and the intensity of colour formed varied amongst the plants and species. The main cause behind is the presence of numerous enzymes and various phyto- constituents (phenolics, terpenoids, polysaccharides and flavonoids) in the extract of different plant species (Huang et al., 2007). 


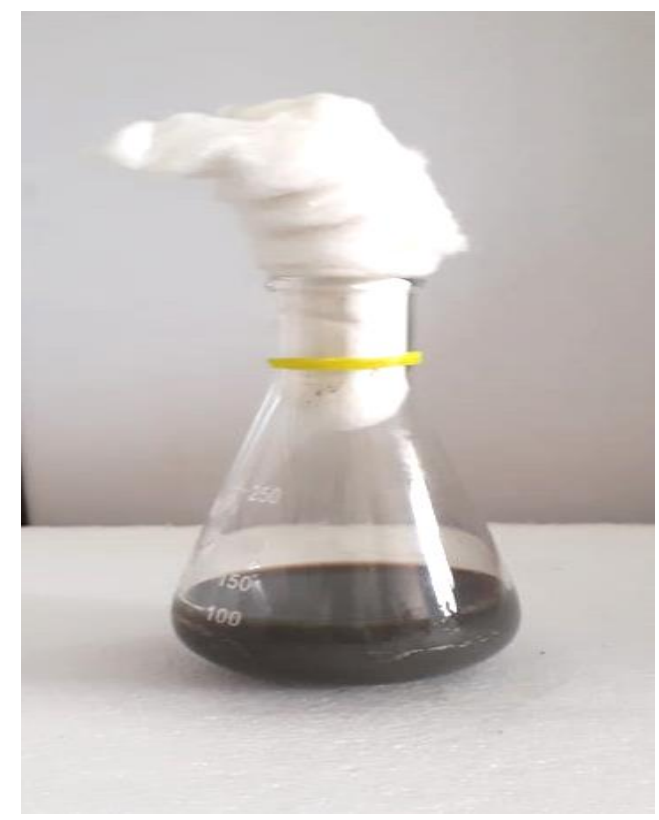

(A) Flower extract of Allamanda neriifolia

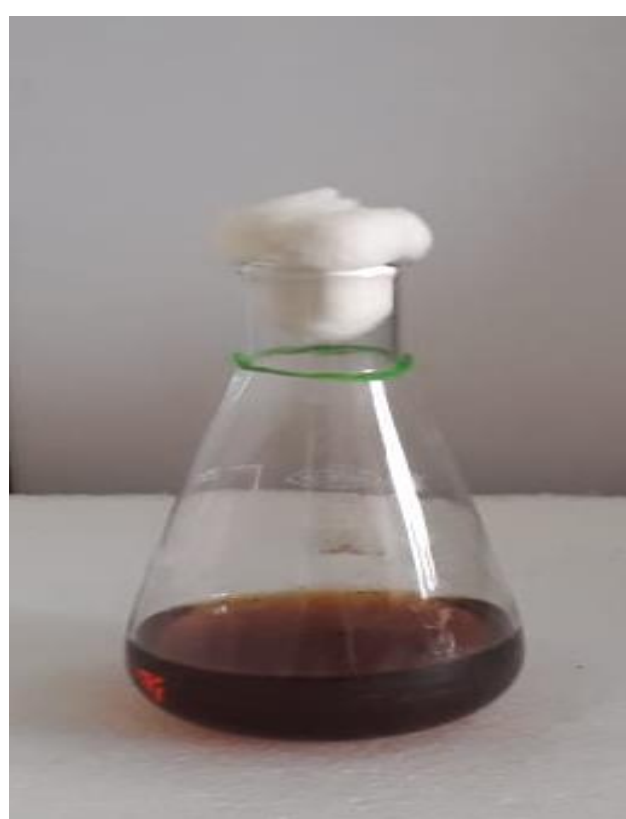

(B) $\mathrm{AgNO}_{3}$ with the flower extracts of Allamanda neriifolia forming AgNPs

Photograph showing the colour change pattern during nanoparticle synthesis; (A) crude flower extract of Allamanda cathartica (B) $\mathrm{AgNO}_{3}$ with the flower extract forming AgNPs after $8 \mathrm{~h}$ of incubation.

However, the reaction time and the intensity of colour formed varied amongst the plants and species. The main cause behind is the presence of numerous enzymes and various Phyto-constituents (phenolics, terpenoids, polysaccharides and flavonoids) in the extract of different plant species.

Our result indicates the colour change in the flower extract within $1 \mathrm{~h}$ of incubation. However, the maximum intensity of colour change was observed after $8 \mathrm{hr}$ of the reduction reaction with $\mathrm{AgNO}_{3}$. The presence of abundant phytochemicals such as alkaloids, flavonoids, saponins, terpenoids, steroids and proteins in theflower extract of Allamanda neriifolia appears to be responsible characterisation of silver nanoparticles.

\section{Effect of AC-AgNPs on UV-Visible spectroscopy}

The UV-Vis spectroscopy proved to be very useful technique for the characterization of invitro plant extracts after the formations of AgNPs. UV-Vis absorption spectrum of the AgNPs has been monitored and recorded by taking reading at regular intervals as shown in Figures 1. In the present study, we observed that UV-Vis spectroscopy analysis indicated a sharp plasmon resonance at around $450 \mathrm{~nm}$, which was specific for AgNPs (Figure1). It is well known that AgNPs shows a yellowish-brown colour in aqueous solution; this colour arises from excitation of surface plasmon vibrations in the metal nanoparticles (Kanipandian et al., 2014). Similarly, several researchers reported that the absorption spectrum between 400 and $480 \mathrm{~nm}$ due to surface plasmon resonance in silver nanoparticles (Anandalakshmi et al., 2016; Swamy et al., 2015). 


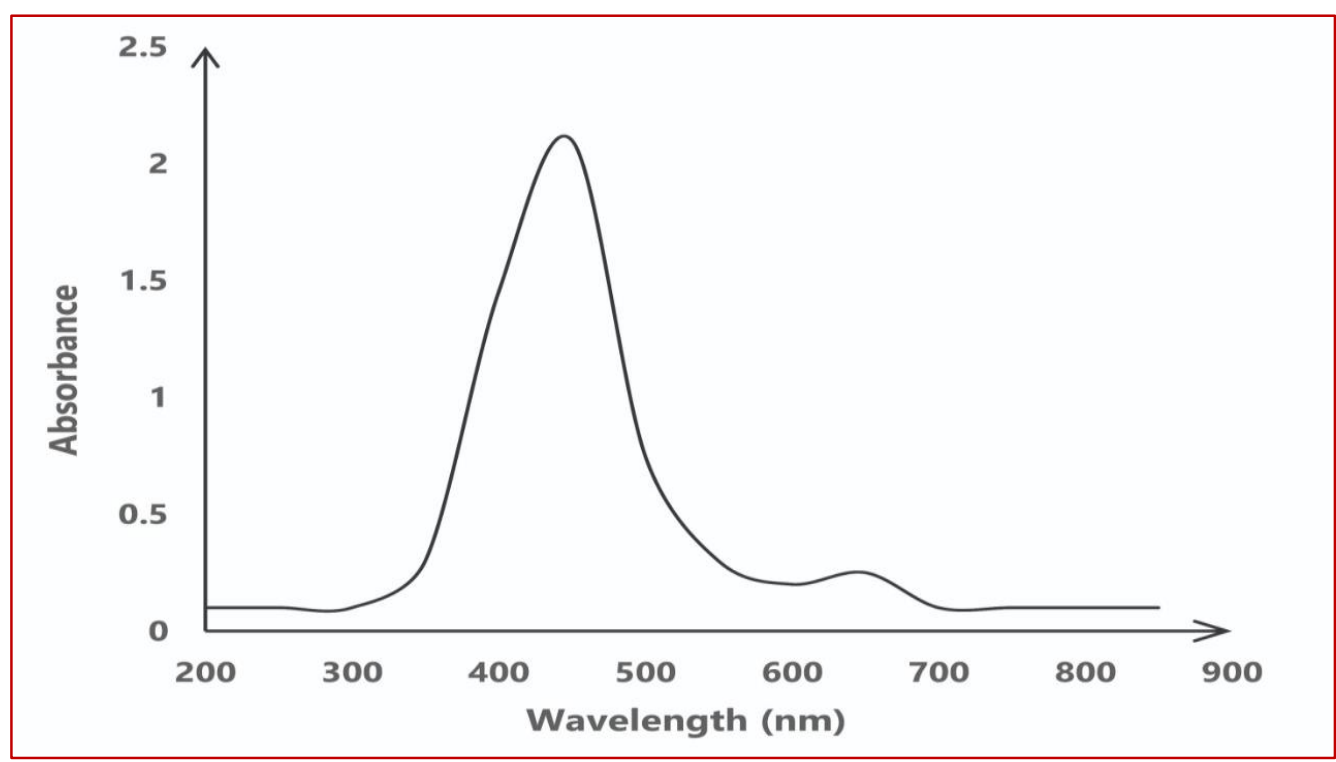

Figure 1. UV-Vis spectrum of the silver nanoparticles synthesized by flower extract of Allamanda neriifolia .

\section{Effect of AC-AgNPs on Fourier-transform infrared spectroscopy (FTIR)}

FTIR has become an important tool in identifying the functional groups present in the interaction between metal particles and biomolecules which are responsible for the bioreduction of AgNPs and also functioning as capping and stabilizing agents. Figure 2 represent the FTIR spectrum of the AN-AgNPs. The observed intense bands were compared with standard values to identify the functional groups. The results of FTIR measurement of this study exhibits eight different stretching bonds are shown at $3418.45 \mathrm{~cm}^{-1}, 2921.33 \mathrm{~cm}^{-1}$, $2851.30 \mathrm{~cm}^{-1}, 1596.70 \mathrm{~cm}^{-1}, 1383.91 \mathrm{~cm}^{-1}, 1038.17 \mathrm{~cm}^{-1}, 564.16 \mathrm{~cm}^{-1}$ and $435.38 \mathrm{~cm}^{-1}$. Intense FTIR band of silver nanoparticles at $3418.45 \mathrm{~cm}^{-1}$ denotes the presence of amine, amide compounds; O-H stretch.2921.33 cm-1 and $2851.30 \mathrm{~cm}-1$ denotes the presence alkane; CH stretch. $1596.70 \mathrm{~cm}-1$ and $1383.91 \mathrm{~cm}^{-}$may correspond to nitro compounds, aromatic and Alkanes, aldehydes, fluroide denotes the $\mathrm{C}-\mathrm{H}$ stretch. Further, the additional bands at $1038.17 \mathrm{~cm}^{-1}$ denotes the alcohol, aliphatic amines, $564.16 \mathrm{~cm}^{-1}$ and $435.38 \mathrm{~cm}^{-1}$ indicates Alkyl halide, halogen and aryl disulphides and S-S stretch. Previous researchers carried out the FTIR to notice the minor changes of primary and secondary metabolites and to recognize the concrete structure of certain plant secondary metabolites. The characteristics functional groups are responsible for the medicinal properties of plants are confirmed by FTIR analysis (Owoyale et al., 2005). Using FTIR spectrum, We can confirm the functional constituents prence in the given parts and extract, identify the madicinal materials from the adulterate, and even evaluate the qualities of medicinal materials. 


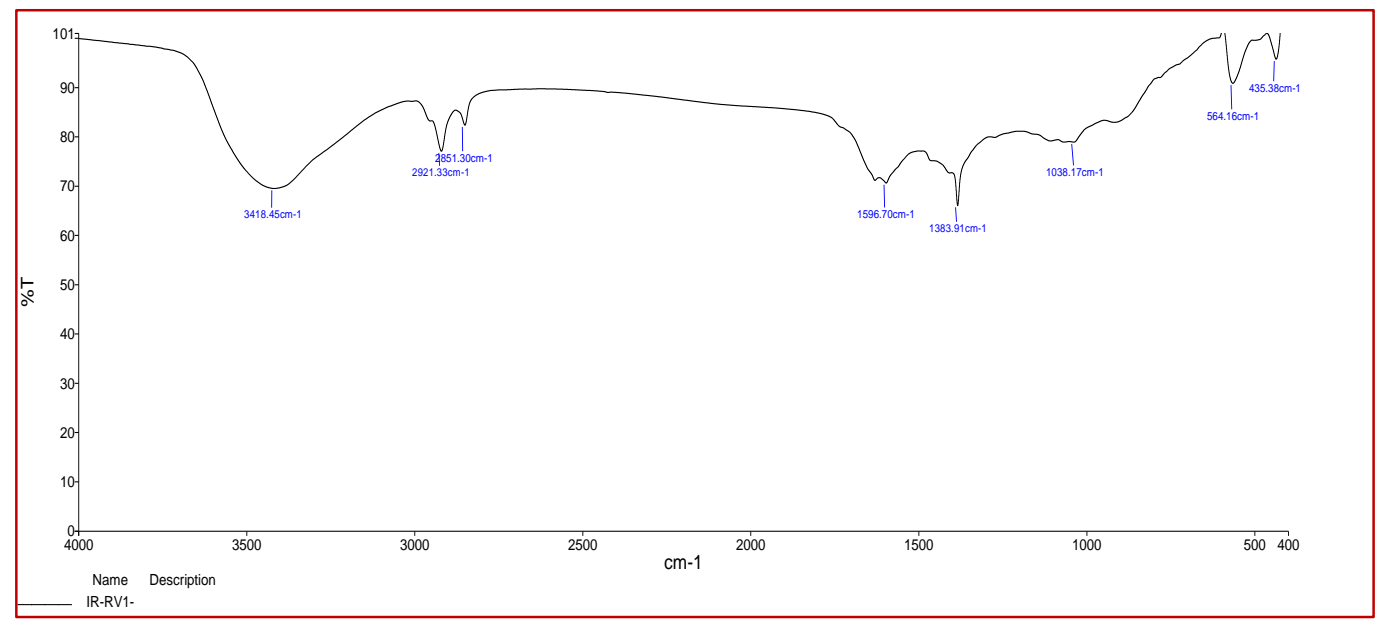

Figure2. Effect of AC-AgNPs extracts on Fourier-transform infrared spectroscopy (FTIR) analysis.

\section{Effect of AC-AgNPs extract on scanning electron microscopy (SEM) for morphological analysis}

The SEM analysis was performed to study the surface morphology and size of the ANAgNPs. It can be noted that AN-AgNPs was at a size of $50 \mathrm{~nm}$ during the synthesis, with different particle morphology, such as spherical, oval, and triangular. Biomolecules aid the formation of different shaped NPs because of the uncontrolled reduction sites present in them. The AgNPs exhibited an average size of $50 \mathrm{~nm}$ according to SEM (Figure3 ).This feature explained that phytoconstituents present in aq. extract of flower were effectively involved and affected the synthesis of silver nanoparticles. Our results are in conformity with the earlier reports of AgNPs synthesized from various plant species (Bonde et al., 2012; Tripathi et al., 2009; Vivekanandhan et al., 2009).

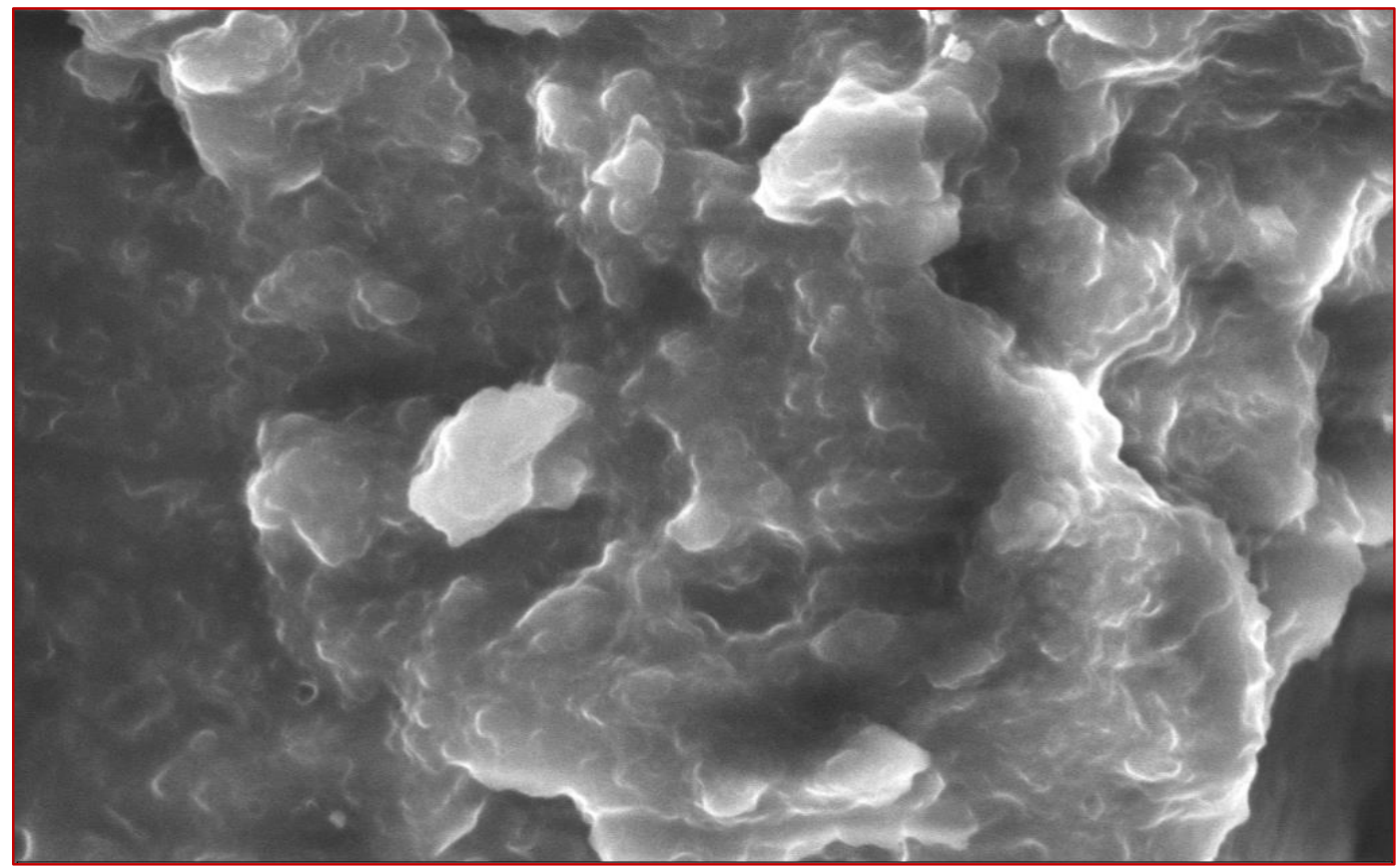

Figure 3 .Effect of AN-AgNPs extract on scanning electron microscopy (SEM) for morphological analysis. 


\section{Effect of AN-AgNPs on cytotoxicity assay by MTT assay in MDA-MB-231 cells}

To assess the nontoxic concentrations of AN-AgNPs for anticancer study, we carried out MTT based cytotoxicity assay in MDA-MB-231 cells. Figure 4 shows the cytotoxic effect of AN-AgNPs on MDA-MB-231 cells was determined by MTT assay. Cells were treated with different concentrations of AgNPs (1-500 $\mu \mathrm{g})$ for $72 \mathrm{~h}$ incubation, which revealed a dose-dependent inhibition of cell proliferation. Maximum cell death was observed at $500 \mu \mathrm{g}$ concentrations. The treatment of1, 5, 10, 20, 40 and $80 \mu \mathrm{g}$ of AN-AgNPs showed above 50\% of cell viability in MDA-MB-231 cells. Further, we found that 100, 200 and 400 $\mu \mathrm{g}$ of AN-AgNPs showed $43 \%, 31 \%, 22 \%$ and $17 \%$ cell viability observed. Hence, nontoxic concentrations (10 and $20 \mu \mathrm{g}$ ) of AN-APNPs were taken for further assay.

Our results obtained from this study are also very well supported with various evidences (Al-Sheddi et al., 2018; Ratan et al., 2020). Moaddab et al (2011) reported that the increase in the cytotoxicity of AgNPs is due to active physical and chemical interaction of silver ions with the functional groups of intracellular proteins, as well as with the nitrogen bases and phosphate groups. The cytotoxic effect of plant mediated AgNPs against various cell lines, such as Hep2, HeLa, and A59 cells were reported in different plant species (AlSheddi et al., 2018; Praburaman et al., 2016; Ramachandran et al., 2020).

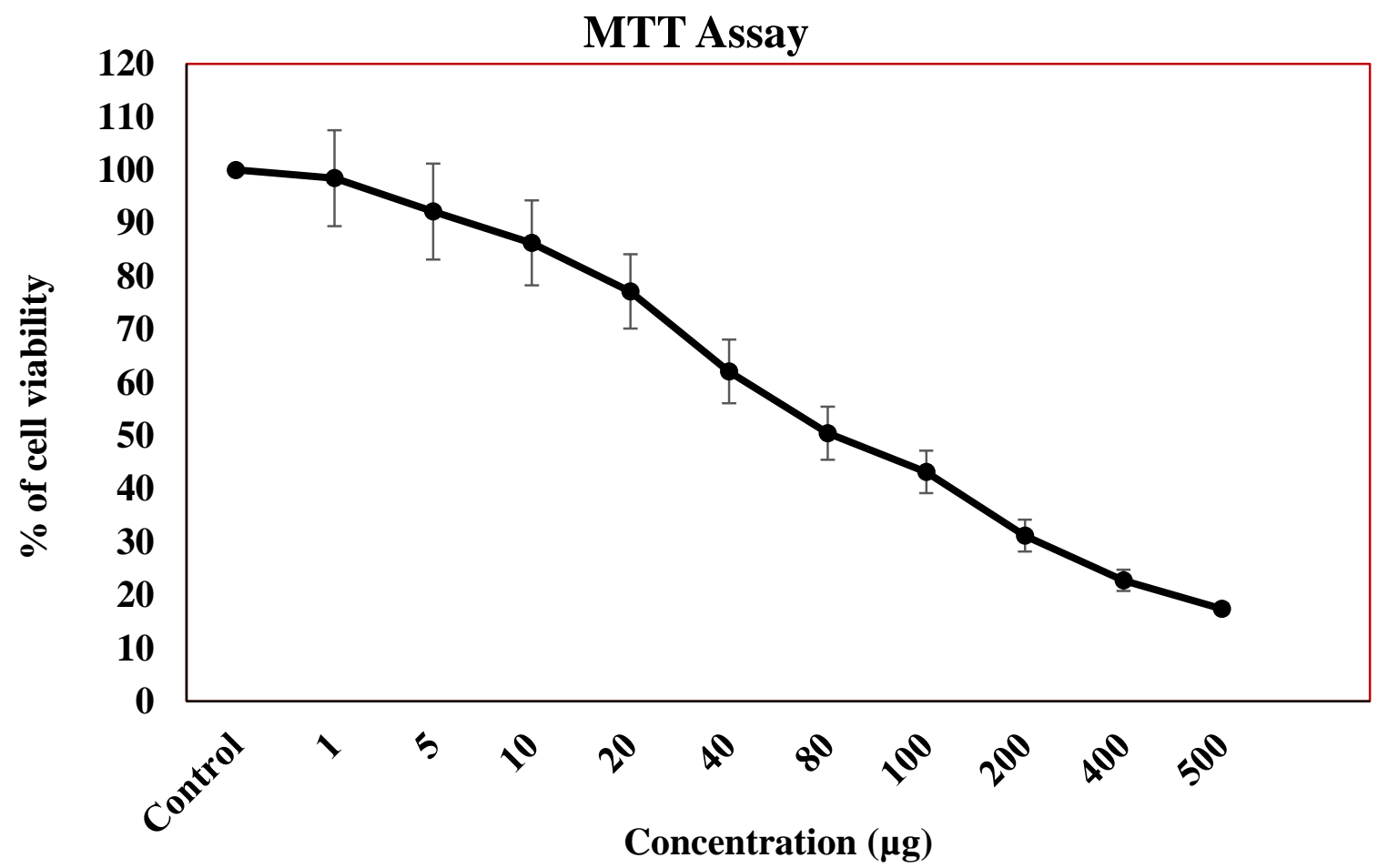

Figure 4. Effect of AN-AgNPs on cytotoxicity assay by MTT assay in MDA-MB-231. Values are given as means \pm SD of three experiments in each group.

In addition, as different parts of the plants (leaves, seeds and roots) were used, this work offers a comparison of the produced NPs in terms of their size, optical properties and antimicrobial activity in one summarising study. The aim of this study is to synthesise AgNPs in an eco-friendly manner using different plant extracts prepared under mild conditions to avoid the loss of thermally unstable compounds. Successfully prepared AgNPs were characterised, and their antibacterial activity in vitro was evaluated. The novelty of this study 
lies in the utilisation of a rich plethora of plant extracts and a simplified synthetic approach for the preparation of AgNPs directly in the UV-Vis cuvette, which enables immediate monitoring of the reaction progress.

\section{SUMMARY AND CONCLUSION}

Silver nanoparticles (AgNPs) were used due to their unique properties and known effects in cancer treatment. AgNPs have many applications in the field of medicine such as antibacterial agents, drug delivery vectors, and physical treatment agents. They have the ability to induce oxidative stress, mitochondrial membrane change, cell death by apoptosis and DNA damage. Allamanda neriifolia, which exhibits antimicrobial, anti-inflammatory, antioxidant effects, antimutagenic, anticancer, antitumor and antidiabetic activities.

In the present study, we investigated that the green, facile, Simple, inexpensive synthesis of silver nanoparticles from Allamanda neriifolia in aqueous medium without using any hazardous chemicals. The UV-Vis spectroscopy \& FTIR affirmed

the formation of silver nanoparticles. SEM image showed spherical shape with an average particle size of less than $50 \mathrm{~nm}$. Furthermore, we demonstrated the biosynthesis of silver nanoparticles (AgNPs) for the first time, via a single-step reduction of silver ions using Allamanda neriifolia plant and its anticancer potential against human breast cancer (MCF-7) cells. Our results showed that biosynthesized AgNPs (AN-AgNPs) induced a concentrationdependent cytotoxicity in MCF-7 cells. AN-AgNPs were also found to induce oxidative stress as observed by the increase in ROS and apoptosis.

Our findings suggest the anticancer potential of biosynthesized AN-AgNPs against human breast cancer cells and could play an important role in the development of new therapeutic agent for the treatment of cancer.

\section{ACKNOWLEGEMENT}

The authors would like to thank the Management, Principal, Head of the Department, and Staff members of Deparment of Biochemistry, Rabiammal Ahamed Maideen College for Women, Thiruvarur, for support in carrying out this work.

\section{REFERENCES}

1. Mohanraj VJ, Chen Y. Nanoparticles-a review. Tropical journal of pharmaceutical research. 2006; 5(1):561-73.

2. Biswas $P, W u$ CY. Nanoparticles and the environment. Journal of the air \& waste management association. 2005;55(6):708-46.

3. Malam $Y, J$ Lim E, M Seifalian A. Current trends in the application of nanoparticles in drug delivery. Current medicinal chemistry. 2011; 18(7):1067-78.

4. Sun Y, Xia Y. Shape-controlled synthesis of gold and silver nanoparticles. science.2002; 298(5601):2176-9.

5. Newman, D.J., Cragg, G.M.: Natural products as sources of new drugs over the last 25 years. J. Nat. Prod. 70, 461-477 (2007).

6. Siu Kuin Wong1, Yau Yan Lim1 and Eric WC Chan2 * Botany, uses, phytochemistry and 
pharmacology of selected Apocynaceae species: A review Pharmacognosy Communications Volume 3 | Issue 3 | Jul-Sep 2013

7. D.Castillo J.Arevalo F.Herrera C.Ruiz R.Rojas E.Rengifo A.Vaisberg O.Lock J.-L.Lemesre H.Gornitzka M.Sauvain, Spirolactone iridoids might be responsible for the antileishmanial activity of a Peruvian traditional remedy made with Himatanthus sucuuba (Apocynaceae) Journal of Ethnopharmacology, Volume 112, Issue 2, 13 June 2007, Pages 410-414.

8. Tiwari, T.N., Pandey, V.B., Dubey, N.K. Plumieride from Allamanda cathartica as anantidermatophytic agent. Phytother. Res., 2002;16(4): 393- 394

9. Mosmann T. Rapid colorimetric assay for cellular growth and survival: application to proliferation and cytotoxicity assay, J Immunol Methods. 1983, 65:55-63.

10. Jiang J, Oberdörster $G$, Biswas $P$. Characterization of size, surface charge, and agglomeration state of nanoparticle dispersions for toxicological studies. Journal of Nanoparticle Research. 2009;11(1):77-89.

11. Philip D. Mangifera indica leaf-assisted biosynthesis of well-dispersed silver nanoparticles. Spectrochimica Acta Part A: Molecular and Biomolecular Spectroscopy. 2011;78(1):327-31.

12. Swamy MK, Akhtar MS, Mohanty SK, Sinniah UR. Synthesis and characterization of silver nanoparticles using fruit extract of Momordica cymbalaria and assessment of their in vitro antimicrobial, antioxidant and cytotoxicity activities. Spectrochimica Acta Part A: Molecular and Biomolecular Spectroscopy. 2015a;151:939-44.

13. Ahmad A, Senapati S, Khan MI, Kumar R, Ramani R, Srinivas V, Sastry M. Intracellular synthesis of gold nanoparticles by a novel alkalotolerant actinomycete, Rhodococcus species. Nanotechnology. 2003;14(7):824.

14. Huang J, Li Q, Sun D, Lu Y, Su Y, Yang X, Wang H, Wang Y, Shao W, He N, Hong

15. J. Biosynthesis of silver and gold nanoparticles by novel sundried Cinnamomum camphora leaf. Nanotechnology. 2007;18(10): 105104.

16. Kanipandian N, Kannan S, Ramesh R, Subramanian P, Thirumurugan R. Characterization, antioxidant and cytotoxicity evaluation of green synthesized silver nanoparticles using Cleistanthus collinus extract as surface modifier. Materials Research Bulletin. 2014;49:494502.

17. Anandalakshmi K, Venugobal J, Ramasamy V. Characterization of silver nanoparticles by green synthesis method using Pedalium murex leaf extract and their antibacterial activity. Applied Nanoscience. 2016;6(3):399-408.

18. Swamy MK, Sudipta KM, Jayanta K, Balasubramanya S. The green synthesis, characterization, and evaluation of the biological activities of silver nanoparticles synthesized from Leptadenia reticulata leaf extract. Applied nanoscience. 2015;5(1):73-81.

19. Bonde SR, Rathod DP, Ingle AP, Ade RB, Gade AK, Rai MK. Murraya koenigii-mediated synthesis of silver nanoparticles and its activity against three human pathogenic bacteria. Nanoscience Methods. 2012; 1(1):25-36.

20. Tripathi A, Chandrasekaran N, Raichur AM, Mukherjee A. Antibacterial applications of silver nanoparticles synthesized by aqueous extract of Azadirachta indica (Neem) leaves. Journal of Biomedical Nanotechnology. 2009;5(1):93-8.

21. Vivekanandhan S, Misra M, Mohanty AK. Biological synthesis of silver nanoparticles using Glycine max (soybean) leaf extract: an investigation on different soybean varieties. Journal of Nanoscience and Nanotechnology. 2009; 9(12):6828-33. 
22. Al-Sheddi ES, Farshori NN, Al-Oqail MM, Al-Massarani SM, Saquib Q, Wahab R, Musarrat $J$, Al-Khedhairy AA, Siddiqui MA. Anticancer potential of green synthesized silver nanoparticles using extract of Nepeta deflersiana against human cervical cancer cells (HeLA). Bioinorganic Chemistry and Applications. 2018; 2018.

23. Praburaman L, Jang JS, Muthusamy G, Arumugam S, Manoharan K, Cho KM, Min C, Kamala-Kannan S, Byung-Taek O. Piper betle-mediated synthesis, characterization, antibacterial and rat splenocyte cytotoxic effects of copper oxide nanoparticles. Artificial cells, nanomedicine, and biotechnology. 2016;44(6):1400-5.

24. Ramachandran V, Arokia Vijaya Anand M, David E, Venkatachalam K, Vijayakumar S, Sankaran V, Balupillai A, Sangeetha CC, Gothandam KM, Kotakadi VS, Ghidan A. Antidiabetic activity of gold nanoparticles synthesized using wedelolactone in RIN-5F cell line. Antioxidants. 2020; 9(1):8.

(Owoyale et al., 2005). 